tors are therefore good absorbers. Neither the secondary radiations nor the coefficients of absorption are proportional to the densities. The secondary radiation does not come from the surface merely, but from a to case of lead to about 3 millimeters for glass, alumicase of lead to about 3 millmeters for glass, alum nium, or paper. It is mainly independent of the stato of the surface. Almost the same amount of radiatio is obtained from solid iron as from iron flings; from liquid and from solid paraffin; from ice and water from paper, millboard, papler-mache, mahogany, pine, and basswood. The theory which agrees most nearly with the results is that the secondary radiation set up in a thin layer is proportional to the density and to the rate of absorption of the primary rays.-A. S. Eve
Philosophical Magazine, December, 1904.

\section{EPICYCLIC TRAINS."}

By ThorNTon KNOWLEs.

IN most cases where toothed gearing is employed, the wheels in gear with each other rotate, while the frame supporting them remains stationary. If, instead of the frame being fixed, one of the wheels constitutes the fixed link, the frame being permitted to revolve round the axis of the fixed wheel, we obtain an epicyclic train. Such a train is capable of producing a high

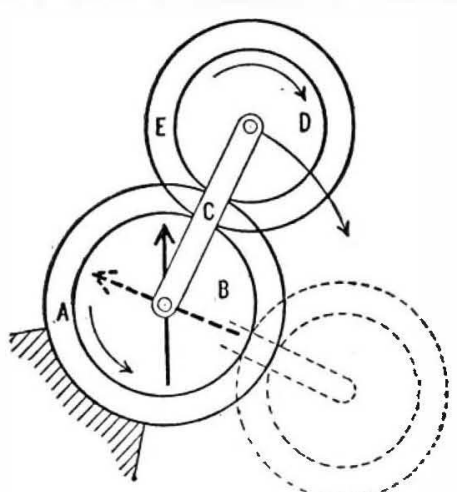

FIG. 1.

velocity ratio with the employment of a very few parts. The simplest case is that shown in Fig. 1, in whic two wheels $A, B$ are in gear and connected by a link $C$. the whe $A$ be ined and the llak $C$ rotates, the motion of the wheel $B$ will be the resultant of two components that of lts own motion relative to the che $C$, and that of the motron of the link $C$ relative to the hxed wheel $A$. In any case where two bodles have motion relatively to a third which is fixed, the angular moveme of the arst to the third is the algebraic sum of the relative angular movements of the first to the second and the second to the third. The angular movement of the wheel $B$ with regard to the wheel $A$ is, therefore, the algebraic sum of the angular move ments of the wheel $B$ relative to the link $C$, and of the link $C$ to the whed $A$. If $N$ be the velocity ratio of the two wheels, for one revolution of the arm $C$ in a clockwise or positive direction the wheel $B$ will have arm will have moved +1 revolution with regard to arm will have moved +1

$$
B \text { 's revolutions }=1+N \text {. }
$$

To make this clearer, suppose the wheels $A$ and $B$ to

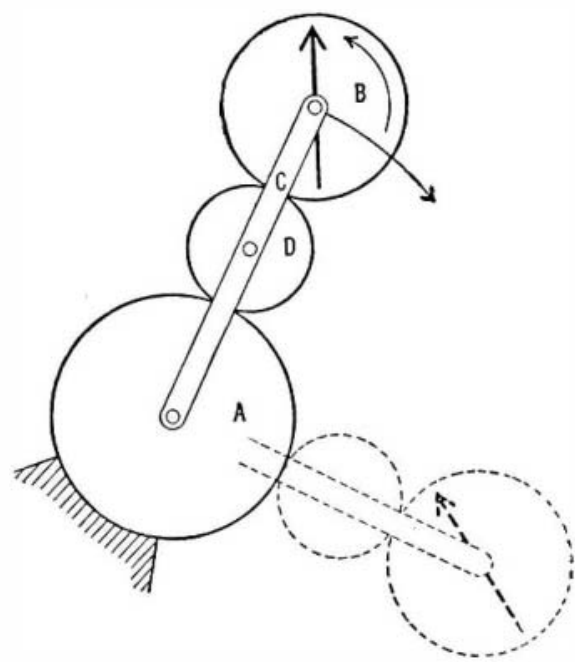

Fra. 2.

have 80 and 60 teeth respectively; then, if $C$ were fixed, for every revolution of the wheel $A$ in a negativ direction the wheel $B$ would make 11-3 revolutions in a positive direction. Now, if while the wheel $A$ is making a single revolution in a negative direction, the whole of the mechanism be rotated one revolution in a positive direction, the wheel $A$ will be stationary, and the wheel $B$ will make 11-3 $+1=21-3$ revolu-

If an idle wheel $D$ (Fig. 2) had been interposed, the direction of rotation of the wheel $B$ would have been negative, and therefore, with other conditions th same as before, the wheel $B$ would make $-11-3+1$ $=-1-3$ revolution. From this it will be seen that if
the wheels $A$ and $B$ were equal in diameter the wheel

the wheels $A$ and $B$

In Fig. 3 is shown what is known as a compoun epicyclic reverted train, in which the wheel $A$ is stil fixed, and the wheel $B$ is mounted loosely on the same shaft as the wheel $A$, from which it is driven by the wheels $D, E$, which are both keyed on one axle. Suppose the whe $A$ and $B$ to have 80 and 60 teeth respectively, as before, whlle the wheels $D$ and $E$ have

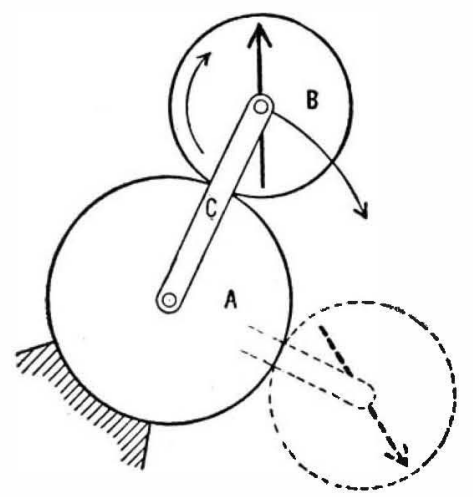

Fig. 3.

wheel $B$ for one positive revolution of the link $C$ would be

\section{$-\left(\frac{90}{80} \times \frac{87}{68}\right)+1=-98+1=-18$ revolution.}

It will be evident that, by making the difference in the diameters of the wheels small, such a train will give the wheel $B$ a very small rotary motion indeed for each revolution of the link $C$.

Fig. 4 shows an example of an epicyclic reverted train in whlch the wheel $A$ is annular. In this form an extra wheel $D^{\prime}$ is usually placed opposite the intermediate wheel $D$, to act as a support. This case is simllar to that shown in Fig. 2, except that the revolutions of the wheel $B$ are positive. Suppose that the wheel $A$ has 56 teeth and the wheel $B 32$ teeth; the wheel $D$ will consequently have 12 teeth, since it is to of the wheel $B$ for one revolution of the link $C$ will be $1+\frac{80}{80}=23$.

The arrangement shown in Fig. 5 is the same as that shown in Fig. 1, except that the wheel $A$ is of the annular type, and the revolutions of the wheel $B$ rela-

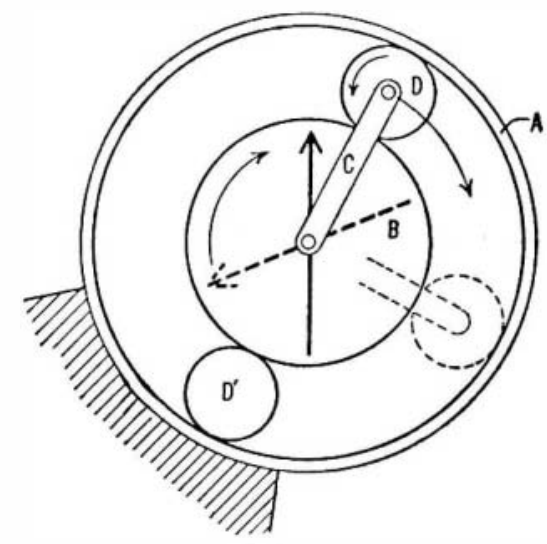

Fra. 4.

tive to the link $C$ are negative. With the same number of teeth as in the example worked out with reference to Fig. 1, the revolutions of the wheel $B$ would be $-\frac{8}{80}+1=-1-3$. In practice, however, it is usual to prevent the wheel
$B$ from rotating on its axis, and to allow the wheel $A$ to rotate. If this were so in the above example, the to rotate. If this wer $A$ would

$$
+\left(1-3 \times \frac{90}{80}\right)=1-4 \text { revolution }
$$

during one revolution of the $\operatorname{arm} C$.

The applications of epicyclic gearing in modern machinery are extremely numerous and varied, many of them exhibiting great ingenuity. The advent of the motor car and the development of bicycles and tricycles have done more to increase the sphere of application of such gearing than any other branch of engineering.

One of the best-known cases of an epicyclic train at the present day is probably the driving gear of the "Bantam" bicycle. This arrangement is also often called the "Crypto" gear. In Fig. 6 is shown a section through the hub of the front wheel of a "Bantam" bicycle. To the frame $H$ is fixed an annular wheel $A$, concentric with the axle $G$, to which the pedals $F$ are secured. $A$ wheel $B$ is formed in one

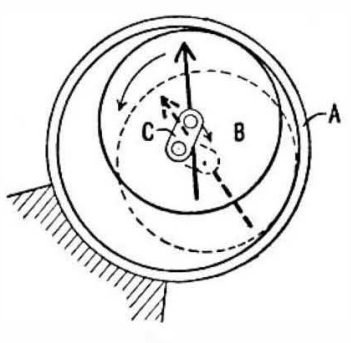

Fra. 5.

with the hub of the bicycle wheel, and is driven by means of the planet wheels $D$ mounted on the disk $C$ which rotates with the cranks $F$. To better comprehend the arrangement of the wheels, it will be well to refer back to Fig. 4, which is a diagrammatic end view be seen that the hub $B$ rotates in the same direction as, but at a greater angular velocity than, the crank higher gear than by driving direct without the intervention of the toothed wheels. With driving gear of (he pro geared up to 66

In Fig. 7 is shown a form of epicyclic gearing of wide application, known as Starley's balance or differentlal gear. The object of this arrangement is to enable the wheels of the driving axle of a motor car or tricycle to have a motlon relative to each other when turning a corner. The axle is divided lnto two parts $L M$, provided with bevel-wheels $A$ and $B$. These are driven by means of the chain wheel $F$, in which are mounted bevel wheels $C D$ in gear with the wheels $A B$, the wheels $C D$ belng free to rotate on the spindies $E$. When the motor car or tricycle is running in a straight line, the two parts $L M$ of the axle rotate at the same rate, and the wheels $A, B, C, D$ remain in the same relative position to each other. When going round a curve, however, the two parts $L, M$ of the

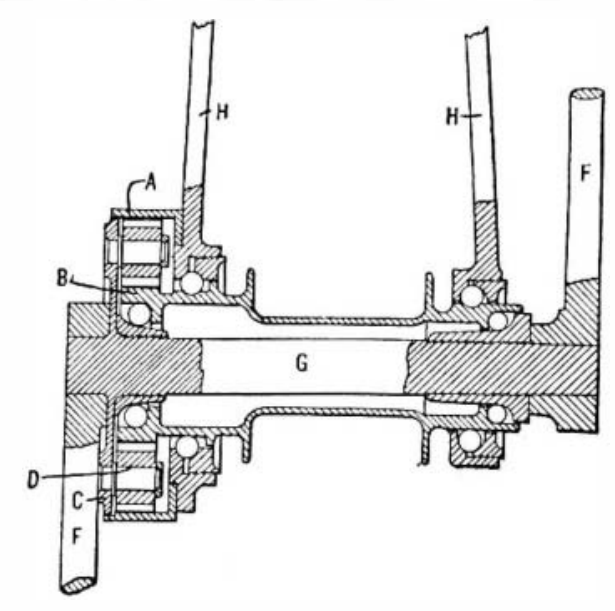

Fia. 6.

the wheels $A B$ to have a relative motion, thus turning the wheels $C D$ on their axes. This rotation of the wheels $C D$ does not in any way infiuence the driving effort of the chain wheel $F$. Practically all present-day motor cars are fitted with differential gear of this or a similar type on their driving axles.

In some forms of bicycles, a bevel-gear similar to the In some forms of bicycles, a bevel-gear similar to the above is fitted in the bottom bracket, and the two wheels $C D$ are driven from the pedal cranks direct. The wheel $B$ is whel $B$ is the large chain wheel for driving the back whel $B$ is the or the che wheel. This form of the gear glves the wheel $B$ two complete revolutions for each revolution of the pedals, thus obver the necessity for any very great diference in the diameters of the two chaln wheels, and The practical application of the type the The practical application of the type of epicyclic in Fig. 8 as applied to the driving in Fig. 8 as applied to the driving mechanlsm of a tions of the or captan. the while the wheel $B$ is prevented from rotating on its which is turned solid with the shaft $B$, and which has which Is turned solld with the shaft , and which has diameters of the pitch circles of the wheels $A$ and $B$.
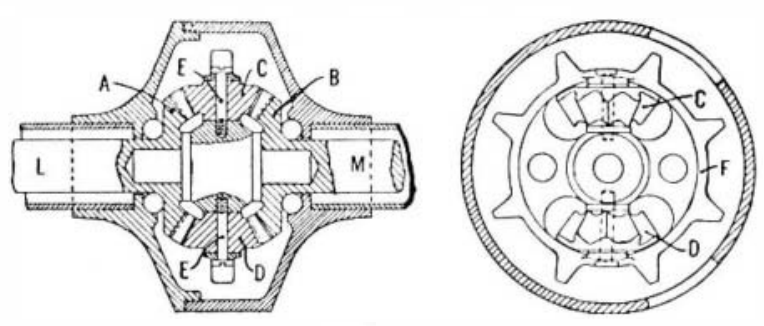

FrG. 7.

To prevent the wheel $B$ from rotating, lugs $Q$ are formed on one side, which slide in vertical grooves in circular disk $D$, which itself is fitted with similar lugs $L$ free to slide horizontally in the groove $E$. Thus it will be seen that by rotating the shaft $F$ the wheel $B$ is carried round in a circular orbit without rotating on its axis, and thereby drives the annular wheel $A$ with a relative velocity depending upon the difference in diameter of the two wheels. The wheel $A$ is mounted loosely on the shaft $F$, and is connected to the winch or capstan by the clutch $K$. Gear of this type has also been applied to differential pulley-blocks and hand steering-gear for ships.

The necessity for rapidly changing the speed of motor cars without altering the revolutions per minute of the driving-motor has been the means of introducing several change-speed mechanisms, many of which have an epicyclic train as one of their constituent parts. The great advantage of such gearing for this purpose is that two speeds, at least, are always possible, since one speed is obtained by the gear running as an epicyclic gear, and another is obtained by locking the wheel train so that it turns as a whole. The change-speed mechanlsm shown in Flg. 9, and known as Beaumont's change-speed gear, affords a good feature, one or more epicyclic trains. This gear may 
be mounted on an intermediate driving shaft, or on the main driving axle $A$ of the car. It comprises three pulleys $L, M, N$, mounted loosely on the shaft $A$. Between these pulleys, and keyed to the shaft $A$, are toothed wheels $B, C$. Adjacent to these wheels are toothed wheels $D, E$, secured by keys to the bosses of the pulleys $L, N$ respectively. Upon a spindle $F$, carried by the central pulley $M$, are mounted four toothed wheels $G, H$, respectively. The wheels $G, H$ rotate together, and form, with the wheels $D, B$ a compound epicyclic reverted train, similar to that shown diagrammatically in Fig. 3. The four wheels $J, K, C, E$ also comprise wheels in the pulley $L$. The pulleys $L$ and $N$ are pro-

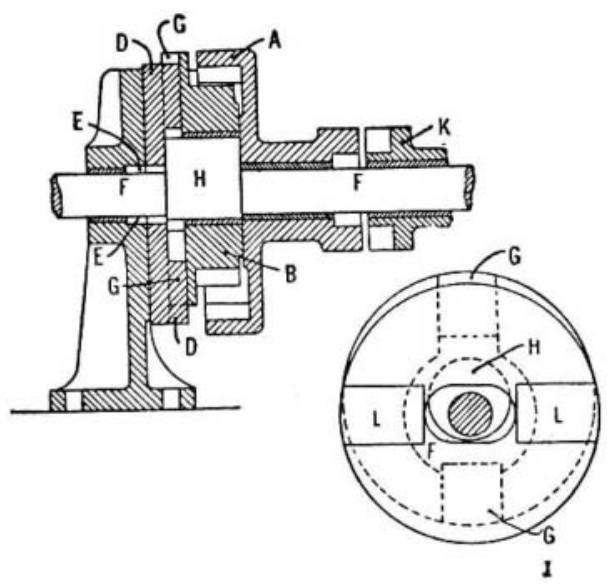

Fig. 8.

vided with brake drums $R, S$, by which either can be held stationary, while the central pulley $M$ is driven. If, for instance, the pulley $L$ be held stationary by the band brake on the drum $R$, the gear wheel $G$ will roll round on the wheel $D$ and carry with it the wheel $H$ in the same direction as the motion of the pulley $M$, thus driving the shaft $A$ by means of the wheel $B$. It will be evident that the pulley $N$ must be allowed to rotate loosely, otherwise the gear would become locked. On the other hand, if the pulley $N$ is braked, and the pulley $L$ is left free to rotate, the gear still being driven from the pulley $M$, the shaft $A$ will be rotated two by ruming the belt on the pulleys $L$ and $M$ or $M$ and by running the belt on the pulleys $L$ and $M$ or $M$ and $N$ at the same the whe and drives the shaft $A$ at its highest speed. If means are provided for braking the pulley $M$, two more speeds pulley pulley $N$. Therefor, by means of this mechanism, the dume $L$ is dispensed the pulley $L$ is dispensed with, and a brake drum $R^{\prime}$ is possible. Further, by choosing sultable proportlons of the varlous toothed wheels in the gear, it is possible to cause one of the methods of

$A$ in a reverse direction.

The designs for change-speed mechanisms are exceedingly numerous, many of them being very ingenlous comble It is in such mechanisms that epicyclic gearing finds

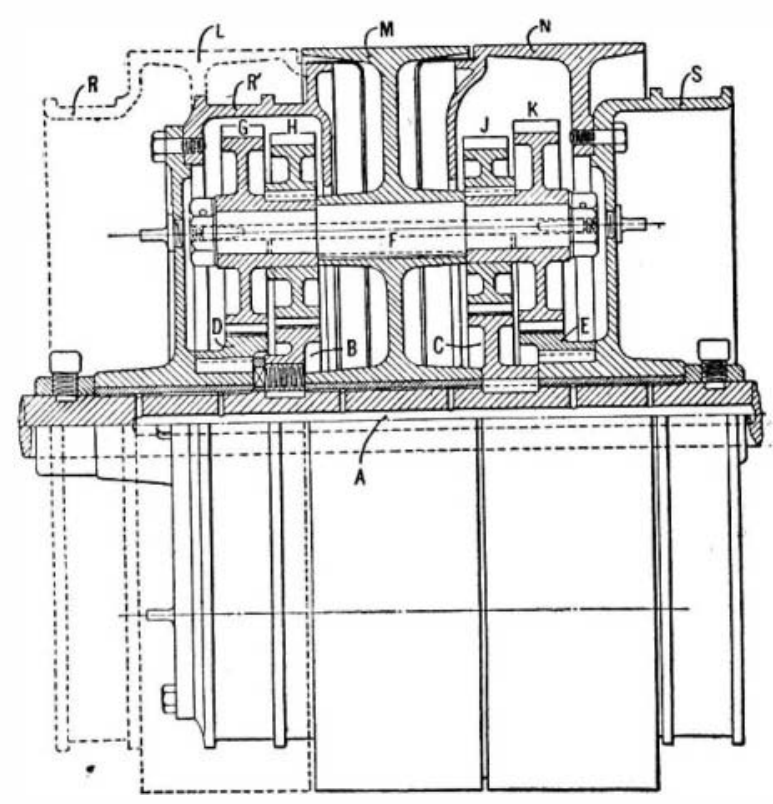

Fig. 9. the greatest number of applications at the present day.
The steering handles of motor cars are also fitted The steering handles of motor cars are also fitted
with a compound epicyclic reverted train in order that the steering may be what is known as "lock steering," or irreversible; that is, the tendency of the ing," or irreversible; that is, the tendency of
wheels to rotate the steering handle is prevented.

During recent years most of the large structural engineering and shipbuilding firms have fitted their yards with a complete installation of compressed air for working small tools. By this means the work on large structures, such as bridges and ships, has been considerably simplified and lessened. As a result of such a universal adoption of compressed air as a motive power, the various pneumatically-operated tools have heen considerably improved. As a rule, the com- pressed air motors used for driving these tools run at a means must therefore be adopted to reduce this speed, and this has led to the application of epicyclic gearing in connection with such compressed air motors, one of the most notable being that shown in Fig. 10, whic is a section of a Boyer pneumatic drill. The compressed air motor comprises three cylinders $A$ set at $D$ which act as distributing $E$, and pivoted on spindle ing on the same crank-pin $B$. This crank-pin $B$

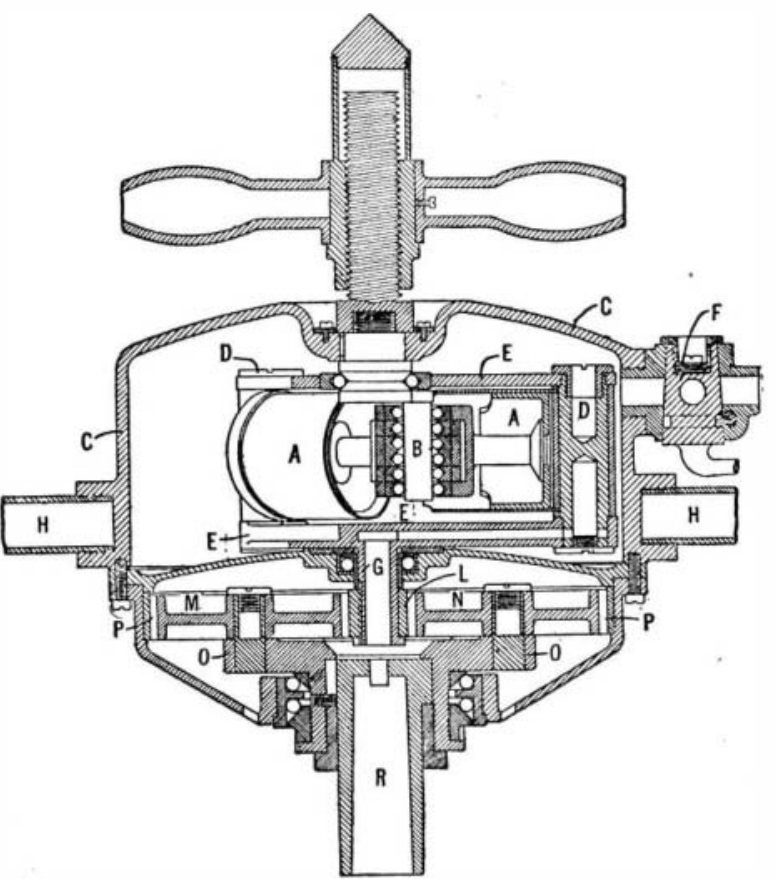

Fia. 10.

fixed to the outer casing $C$ of the machine, and the three cylinders $A$ therefore revolve round it upon the admission of air under pressure by the valve $F$. The machine is rigged up against the work in a simila fashion to an ordinary ratchet brace, and is kept from rotating by the handles $H$. At the lower portion of the hollow shaft $G$, which is in one with the frame is keyed a toothed pinion $L$. In gear with this pinio are two wheels $M, N$ rotating on spindles fixed to the crosshead 0 , these wheels being in turn in gear with an annular wheel fixed in the outer casing. By this arrangement the pinion $L$, being rotated by the moto cylinders $A$, causes the wheels $M, N$ to rotate the crosshead $O$ at a reduced speed. The motion of the crosshead is transmitted directly to the chuck $R$ in which the drill or other tool is held. In this form of driving mechanism the power being applied on opposite sides of the engine shaft, instead of on one side only as in the earlier forms of pneumatic drills, the force on the gear are perfectly balanced.

Another example of epicyclic gearing in modern machinery is illustrated in Fig. 11, which shows a portio of Brown's hydraulic steering-gear. The steerin wheel $A$ is mounted on a shaft $F$, and operates the rack
$G$ by means of the pinion $H$. At each end of the rack

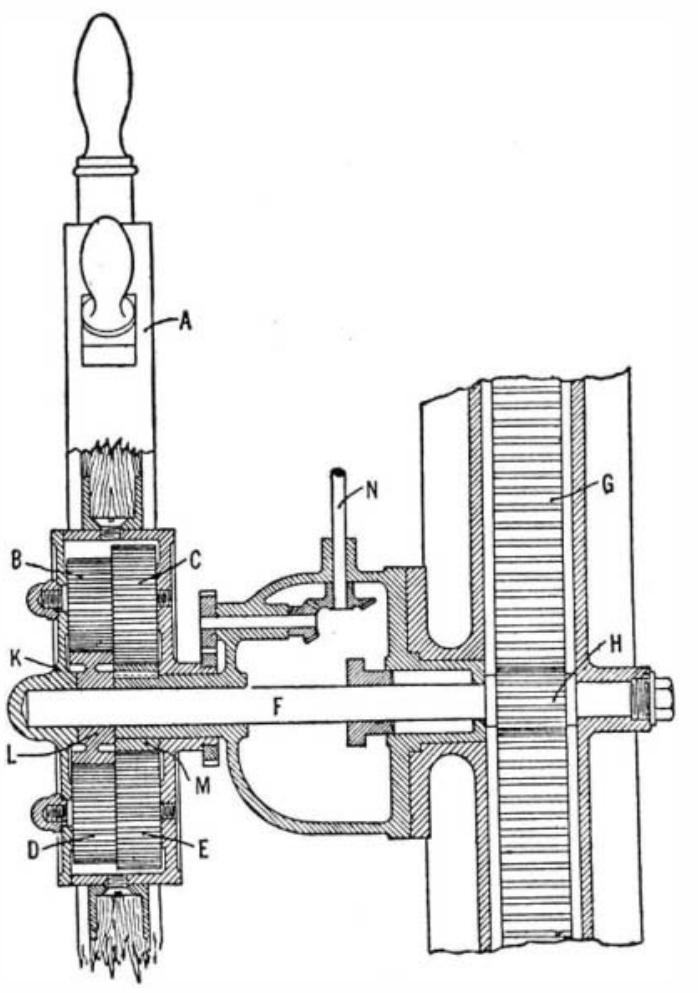

Fig. 11 .

is fitted a piston working in an hydraulic cylinder, not shown in the figure. The movement of these pistons communicates by hydraulic pressure pipes the motion of the steering wheel to the tiller. Since by direct driving it would not be possible to obtain sufficient pressure on the piston to operate the tiller, recourse is had to epicyclic gearing to effect this object. The gearing is fitted in the hub $K$ of the steering-wheel and comprises two pairs of wheels $B, C, D, E$ in gear with a wheel $L$ on the shaft $F$, and a wheel $M$ attached to the frame of the apparatus. The rotation of the shaft for one revolution of the steering-wheel $A$ is ar ranged to be a very small amount, thereby producing the requisite pressure. A pointer, for the purpose of ndicating the position of the rudder, is operated from the shaft $N$; its rotation is effected by ordinary toothe and bevel gearing from the hub $K$ of the steeringWheel. In a recent form of Brown's steam steerin gear, the steering engine is mounted on the tiller with the controlling valve co-axial with the rudder-post This valve is operated by means of an epicyclic train similar to that shown diagrammatically in Fig. 4. The velu valve spichle is which is actuated from the steering wheel on the capwhich is actuat

The above examples only serve to indicate the wide range of the applications of the epicyclic train. Several other uses might be mentioned which have either been introduced or greatly improved during the last few years. Such a list would include mechanism for operating and reversing the tables of printing machines, for regulating the tension of the yarn in spinning machinery, for lathes, for motor boat propelling paratus, for hoisting machinery, for turning turrets n warships, for kinematographs and tube-expanders.

The great adaptability of this form of gearing will e obvious when the wide (a) considered.

THE ELEMENTS: VERIFIED AND UNIFIED. ${ }^{1}$

IT is the sad duty of the retiring chairman of this section to chronicle the death of two members. One of them, James Francis Magee, B.S., University of Penn sylvania, 1887, devoted his life chiefly to commercia pursuits, in which he was most successful. He joined the association at the fifty-first meeting, being one of the youngest members. The other was $H$. Carrington Bolton, Columbia, 1862 (Ph.D. Göttingen, 1865), who with the exception of four (Gibbs, Boye, Brush and Hilgard), was the senior of the section, having joined a the seventeenth meeting. I beg permission to quote from an article of his in the American Chemist, 1876, the year following his elevation to fellowship in the association, as it exemplified in telling words one of the great aims in his life, with the fruitful accomplishment of which you are familiar:

"So rapid are the strides made by science in this progressive age and so boundless is its range, that those who view its career from without find great difficulty in following its diverse and intricate pathways, while those who have secured a footing within the same road are often quite unable to keep pace with its fleet movements and would fain retire from the unequal contest. It is not surprising, then, that hose actually contributing to the advancement of erly upward and onward, should neglect to look back upon the labors of those who precede them and should sometimes lose sight of the obligations which sclence owes to forgotten generations." 2 His numerous contributions to and intimate knowledge of the history of chemistry, his gentle and generous sympathy, aided and stimulated many active in research or technical applications of chemistry. His monumental bibliographies put out by the Smithsonian
Institution are masterpieces. The grief and keen regret of his loss are not confined to one nation.

On another occasion it has been the good fortune of him who has the honor of addressing you to-day to indicate that events of literary moment, governmental modifications, inventions and forward stridings in science, have apparently accommodated themselves to historical periods during the past century. ${ }^{3}$ Striking, novel facts and fancies, gleaned in the realm of inorganic chemistry, have crested not a few of the high waves of those human tides that beat against the coasts of the untried and unknown.

The human mind knows by contrasts. For the day we have night; for the good there is evil. Where man would have a God he also had a devil; for the true there is the false; the verified and unverifled. The false may be true through ignorance; the true may be false in the light of new knowledge. Or, as Hegel put it, "Sein und das nicht Sein sind das Nämliche."

Is matter continuous or discrete? argued the opposed schools of Grecian philosophy led by Leucippus, Democritus and Epicurus and dominated by Aristotle. Despite the clarity of the statements of the Roman Lucretius, ${ }^{4}$ the atomic hypothesis received scant attention until the seventeenth century of the Christian era when Galileo's experimental science assailed Aristotelian metaphysics and demanded verification of the premises of that philosophy which had governed all the schools of Europe for two thousand years. ${ }^{5}$ While Gassendi, Boyle, Descartes, Newton, perhaps Boscovich, Lavoisier, Swedenborg, Richter, Fischer and Higgin bad to do with our modern atomic theory, Dalton one 1Address of the vice-prestdent and chairman of Section $C$
Chementstry, of the Amercan Association for the Advancement 2 "Notes on the Early Literature of Chemmstry-The Book
at the Balance of Wisdom," New York Academy of Sciences, Mas 29, 1876.
s."The Rare Earth Crusade; What it Portends, Sclentifically
and Technically," Sclence, N. S., XVII., 722-781. - "Nature reserving these as seeds of things
Permits in them no minlsh nor decas:
They can't be fewer and they can't be less."

galn, of compounds-
"Decas of some leaves others free to grow
And thus the sum of things rests unimpaire.

And thus the sum of things rests unimpaired." 